\title{
Coarsened Exact Matching of Excisional to Plasma-Ablative Ab Interno Trabeculectomy
}

\author{
Dakroub M. ${ }^{1}$, Verma-Fuehring R. ${ }^{1}$, Strzalkowska A. ${ }^{1}$, Hillenkamp J. ${ }^{1}$, Al Yousef ${ }^{1}{ }^{1}$ and Loewen N.A. ${ }^{1,2}$ \\ 1. Department of Ophthalmology, University of Würzburg, Würzburg, Germany \\ 2. Artemis Eye Center, Frankfurt, Germany \\ * Correspondence: Nils Loewen, Department of Ophthalmology, University Hospital Würzburg, Josef- \\ Schneider-Straße 11, 97080 Würzburg, Germany; loewen.nils@gmail.com
}

\begin{abstract}
Purpose: To compare ab interno trabeculectomy by trabecular meshwork excision to plasma-mediated ablation in primary open-angle glaucoma.

Methods: Retrospectively collected data of TrabEx+ (TEx, n=56) and Trabectome $(T, n=99)$ were compared by coarsened exact matching to reduce confounding and matched based on baseline IOP and age. Primary outcomes were IOP and number of glaucoma medications. Complications and need for additional glaucoma surgery were assessed. Patients were followed for up to one year.
\end{abstract}

Results: 53 TEx could be matched to T. Baseline IOP was $16.5 \pm 4.6 \mathrm{mmHg}$ in both; age was $73.7 \pm 8.8$ and $71.5 \pm 9.9$ years in TEx and $\mathrm{T}$, respectively. TEx were taking more medications than $\mathrm{T}(\mathrm{p}<0.001)$. IOP was reduced to $14.8 \pm 4.3$ in TEx and to $13.4 \pm 3.4$ in $\mathrm{T}$ at 6 months, and to $14.9 \pm 6.0(\mathrm{p}=0.13)$ in TEx and to $14.1 \pm 3.8 \mathrm{mmHg}$ (all $\mathrm{p}<0.05)$ in $\mathrm{T}$ at 12 months. Medications were reduced at both 6 and 12 months $(p<0.05)$. No differences were seen between TEx and $\mathrm{T}$ at 6 and 12 months. In TEx, only one serious complication occurred, and two patients required further glaucoma surgery.

Conclusion: Although both groups had a baseline IOP considered low for ab interno trabeculectomy, IOP and medications were reduced further at 6 and 12 months. IOP reduction did not reach significance in TEx at 12 months. The inter-group comparison did not reveal any significant differences. Both had a low complication rate.

Keywords: Glaucoma; TrabEx; Trabectome; ab-interno trabeculectomy; prognosis; intraocular pressure

\section{Introduction}

$\mathrm{Ab}$ interno ablation, excision, and disruption of the trabecular meshwork (TM) can lower intraocular pressure (IOP) effectively in primary open-angle glaucoma (POAG) when the outflow resistance is at the most proximal part of the conventional outflow tract [1]. Secondary open-angle glaucomas with a pathomechanism that principally affects the TM respond to these procedures equally well (pigmentary [2, 3], and anti-VEGF-agent-induced [4] glaucoma), or better than POAG (pseudoexfoliation [5], steroid-induced glaucoma [6]).

Plasma-mediated ablation of the TM with the Trabectome (T; MicroSurgical Technology, Redmond, WA, USA), has been available to surgeons since 2004 [7], while excisional removal was first introduced in 2014 [8, 9]. Interestingly, dual blade excision of tissue in the angle was invented earlier (1989), but was only used to obtain biopsies [10]. Current leading modalities of excisional TM removal are the TrabEx (TEx; MicroSurgical Technology, Redmond, WA, USA) and the Kahook 
Dual Blade (KDB, New Word Medical, Rancho Cucamonga, CA, USA). The absence of a bleb and the theoretical limit of maximal IOP reduction to the level of episcleral venous pressure constitute important safety features of T, TEx and KDB because they avoid hypotony or bleb-related complications so common to filtering surgeries [11].

There are advantages to both plasma-mediated ablation $(\mathrm{T})$ and dual blade excision (TEx and KDB). T enables the atraumatic molecularization and aspiration of the TM [7]. In contrast, TEx and KDB can be used to obtain TM samples [9] and excise the TM without the need to purchase a high-frequency alternating current generator as an additional, external device. An advantage of TEx over the KDB is the active irrigation and aspiration that improve visibility and anterior chamber stability [12]. A downside of both the TEx and KDB is that a dual cut of the TM cannot always reliably be initiated, potentially allowing remaining TM lips to reapproximate, as can happen in trabecular disruption by trabeculotomy [13]. Literature regarding TEx is limited to studies of its efficiency in obtaining TM biopsies in vivo [9] and ex vivo porcine anterior segments [2, 12, 14].

Given the effectiveness of excisional ab interno trabeculectomy in clinical studies $[8,15,16]$, we hypothesized that subtle differences between $T$ and TEx could be discovered by applying a modern statistical method to existing data in the form of matching. Matching reduces confounding factors by enabling a highly balanced comparison $[17,18]$. In two studies where matching was used, we found that $\mathrm{T}$ performed significantly better than trabecular micro-bypass implants $[18,19]$. This is something that can be obscured when unmatched averages are compared and is not eliminated by, e.g., comparing two procedures in the fellow eyes of the same individual [20].

\section{Methods}

This study was approved by the institutional review board (IRB) of the University of Würzburg (Protocol ID: 21122020 1920). Due to its retrospective nature, informed consent was waived. The study abided by the principles stated in the declaration of Helsinki and its subsequent amendments. We performed a chart review of all patients with open-angle glaucoma who had undergone surgery from February 2020 to February 2021. The surgical indication for T and TEx was an IOP value above target level on maximally tolerated topical treatment, or a desire to reduce the number of glaucoma medications. Those with a follow-up of 6 months or longer were matched using coarsened exact matching (CEM). We excluded patients with secondary glaucoma and those with a follow-up of fewer than six months. Patients younger than 20 years of age or who underwent prior glaucoma surgery on the same eye were also excluded.

Baseline parameters recorded included age, gender, type of glaucoma, date of surgery, visual acuity, intraocular pressure, and the number of IOP-reducing medications. Data on postoperative complications and subsequent ocular surgeries were also gathered. Visual acuity, IOP, and the number of medications were obtained one day before surgery, as well as at each follow-up visit. All IOP measurements were carried out using Goldmann applanation tonometry (HaagStreit, Köniz, Switzerland). Surgical success was defined as a total IOP decrease $\geq$ $20 \%$ with a final IOP $\leq 21 \mathrm{mmHg}$. In addition, patients who had a medication reduction of one drop or more were also considered to have undergone a successful intervention.

Surgical Intervention

page 2 of 12 
The patient's head was tilted $45^{\circ}$ away from the surgeon. After a temporal clearcorneal incision, light pressure was applied to the posterior lip of the incision to release a small amount of aqueous humor. The resulting hypotension, caused venous blood to reflux into Schlemm's canal (SC) and helped identify the proper target. The tip of the instrument was inserted. The TM was visualized with a goniolens, and then ablated (T) or excised (TEx) along approximately $120^{\circ}$ of the nasal circumference. Subsequent blood reflux indicated a successful removal of the $\mathrm{TM}$ and the inner wall of SC. After retraction of the instrument, the anterior chamber was reformed by injecting balanced salt solution (BSS) and the corneal incision was sealed by hydration. The postoperative treatment was similar for both procedures and consisted of dexamethasone eye drops tapered by one drop per week and antibiotic eye drops for one week; glaucoma drops were continued as deemed necessary.

\section{Statistical Analysis}

Our power calculation indicated that 48 patients would be needed in the TrabEx group to compare them to Trabectome patients and achieve a statistical power of $80 \%$. Data was analyzed using SPSS Statistics (Version 26, IBM, New York, USA). Means and standard deviations were calculated for continuous variables, while frequencies and percentages were used for categorical variables. The Kolmogorov-Smirnov test was run to test for normal distribution of data. Patients were matched by IOРв $_{\text {в }}$ and age, the two most important determinants of postoperative IOP [21]. To compare the means of the primary outcome parameters, a t-test or a Mann-Whitney $U$ test was used. Surgical success was reported as a dichotomous variable and compared using a Chi-square test. A p-value of 0.05 or less was considered statistically significant.

\section{Results}

Of 75 TEx patients, 53 could be matched to $\mathrm{T}$ by age and IOP using CEM. Table 1 shows the baseline characteristics of the matched groups. There were no differences in age, gender, glaucoma type, baseline IOP and visual acuity between both groups (all p-values $>0.05)$. Matched baseline IOP was at $16.6 \pm 4.6 \mathrm{mmHg}(\mathrm{p}=$ $0.97)$. Age was $73.7 \pm 8.8$ years in TEx and $71.9 \pm 9.9$ years in $T(p=0.24)$. TEx were taking more medications, $2.1 \pm 1.4$, than T with $1.4 \pm 1.1(\mathrm{p}<0.001)$. Most patients $(>$ $80 \%$ in both groups) had a simultaneous phacoemulsification/intraocular lens insertion (Phaco/IOL) with their TEx or T procedure. POAG patients represented the majority, $73.6 \%$, in both groups; LTG comprised the remaining $26.4 \%$.

From a baseline IOP of $16.6 \pm 4.6 \mathrm{mmHg}$, our 6 months postoperative mean IOP was reduced to $14.8 \pm 4.3 \mathrm{mmHg}$ in TEx and $13.4 \pm 3.4 \mathrm{mmHg}$ in $\mathrm{T}$. Both values were significantly lower than baseline ( $\mathrm{p}<0.01$ for both). At 12 months, IOP levels in TEx were similar to baseline $(14.9 \pm 6.0, \mathrm{p}=0.135)$. $\mathrm{T}$ was significantly lower than baseline $(14.1 \pm 3.8, \mathrm{p}<0.001)$. Both groups took significantly fewer glaucoma medications at 6 and 12 months (Table 2, both $\mathrm{p}<0.005$ ).

In the inter-group comparison, IOP levels at the 6 and 12-month follow-ups were similar ( $p=0.12$ and $p=0.99$, respectively; Table 2$)$. TEx used more glaucoma medications compared to $\mathrm{T}$ ( $\mathrm{p}<0.001$ for both 6 and 12 months). IOP reduction at 6 months was $2.0 \pm 5.0 \mathrm{mmHg}$ in TEx and $3.2 \pm 4.8 \mathrm{mmHg}$ in T. These values at 12 months were $0.6 \pm 5.9 \mathrm{mmHg}$ in TEx and $2.4 \pm 4.8 \mathrm{mmHg}$ in T. There was no significant difference in IOP reduction between both groups at 6 or 12 months $(p=0.41$ and 0.2 , respectively). Medication reduction in TEx and T was $0.43 \pm 1.3$ and $0.88 \pm 1.4$ at 6 months and $0.63 \pm 1.29$ and $0.75 \pm 1.25$ at 12 months, respectively. These values did not differ significantly between both groups $(p>0.05)$. 
Table 3 depicts the unmatched data for each group. There was a significant difference in age between TEx and T patients $(\mathrm{p}=0.002)$. Both, TEx and T showed a significant postoperative IOP decrease at 6 and 12 months (all p-values $<0.05$ ). IOP levels were similar in both groups at all time points (all p-values $>0.05$ ). Similarly to our matched data, compared to their baselines, TEx and T used fewer medications 6 and 12 months postoperatively (all p-values $<0.05$ ) and T needed fewer medications than TEx at both follow-ups (both $\mathrm{p}<0.001^{*}$ ).

Applying success criteria common to minimally invasive surgeries, an IOP decrease of $\geq 20 \%$ or final IOP $\leq 21 \mathrm{mmHg}$, TEx and T where at or exceeded $93 \%$ at six months and $95 \%$ at one year (Table $4 ; \mathrm{p}>0.05$ for TEx vs. T). Using the more stringent criteria of IOP decrease of $\geq 20 \%$ and final IOP $\leq 21 \mathrm{mmHg}$, success was achieved in more than $40 \%$ at six months and in more than $32 \%$ at one year. A success in both IOP reduction and at least one medication reduction was achieved in $15.2 \%$ in TEx and $13.5 \%$ in T at 6 months. These values were $10.0 \%$ (TEx) and $7.7 \%$ (T) at one year, respectively.

Four $(7.5 \%)$ TEx experienced postoperative complications that included toxic anterior segment syndrome $(n=1)$, and cystoid macular edema $(C M E ; n=3)$. Two patients $(3.8 \%)$ required further glaucoma surgeries and received a microshunt (Preserflo, Santen, Osaka, Japan, $\mathrm{n}=2$ ). One $\mathrm{T}$ patient experienced postoperative CME (1.9\%).

\section{Discussion}

In this study, we applied CEM to compare the 1-year outcomes of excisional ab interno trabeculectomy between a newer dual-blade device (TrabEx+, TEx) and established plasma-mediated ablation (Trabectome, $\mathrm{T}$ ). The advantage of matching is that small IOP differences caused, for instance, by wound healing, can be detected. Using matching, we previously found that an IOP increase seen in trabecular bypass stents is absent in ab interno trabeculectomy $[18,19]$. We had observed the difference in IOP reduction around the time a foreign body reaction and fibrosis were observed in other trabecular bypass studies, suggesting this may be the underlying cause [22, 23].

For the present study, we had chosen IOPв and age as the matching criteria because they are the two most important determinants of postoperative IOP, which can diminish the IOP reduction according to the formula $0.73 \mathrm{mmHg} \times$ baseline IOP plus $0.03 \mathrm{mmHg} \times$ age [21]. In contrast, the preoperative number of medications affects the postoperative IOP result only in a minor way, by lessening the response by $0.09 \mathrm{mmHg} \times$ number of medications [21]. Because the difference in the average medication intake was only 0.7 drops, we would expect the IOP reduction difference to be negligible $(0.063 \mathrm{mmHg})$. The match caused our patient baseline demographics to have the same baseline IOP and sufficient similarities in the other variables not to be significantly different, except for the medication intake. Patients who underwent TEx were taking more medications than T. This could imply that the pressure in these patients was more refractory to medical treatment than in T. It is important to point out that this would not have disadvantaged TEx. On the contrary, it is often eyes with more advanced glaucoma, not milder glaucoma, that have a larger response to AIT, possibly because their TM is more diseased and less permeable $[5,24]$. When this larger resistance is removed, a greater total IOP decrease can ensue.

It is remarkable that both TEx and $\mathrm{T}$ did show an IOP reduction despite a relatively low preoperative IOP of $16.6 \pm 4.6 \mathrm{mmHg}$. Such a low preoperative IOP is rather close to the postoperative IOP that was achieved in other studies, for instance, in a retrospective Trabectome analysis [25], where it was $16.5 \pm 2.8 \mathrm{mmHg}$, and in a 
propensity score matched comparison of Trabectome and Baerveldt implants [26], where it was $16.1 \pm 4.1 \mathrm{mmHg}$. Indeed, the preoperative IOP in our present study is almost equal to the computed, typically achievable postoperative IOP. Using a hypothetical patient, a 75-year-old pseudophakic patient with POAG and a baseline IOP of $21 \mathrm{mmHg}$ on two medications, $16.8 \mathrm{mmHg}$ would be expected [21]. TEx and $\mathrm{T}$ appear to be most appropriate for patients who already have a low preoperative IOP if they want to avoid the complications of filtering surgery. It is also appropriate for those, who primarily need cataract surgery but also want to give IOP and medication reduction a chance at the same time. As the low rate of patients who fulfilled both the IOP and the medication success criteria (8-15\%) highlights, the riskier trabeculectomy may be better able to achieve freedom from drops and reduce the IOP by a large amount [27]. The reduced success rate of $T$ in the setting of a low preoperative IOP has already been established before in other studies [28-30].

Despite similar baselines and TEx patients taking more medications to achieve this IOP, there was no statistically significant difference between the postoperative IOP of TEx and T when compared directly. The IOP reduction in TEx was significant at 12 months in the unmatched data, but the focus of our study was to detect differences in outcomes of two already quite similar surgical modalities. The IOP reduction in TEx appeared not to be statistically significant at 12 months in the matched comparison because the match eliminated unmatched data, and also because of the low baseline IOP. A low baseline IOP increases the number of subjects required to detect a before-after difference while maintaining a sufficient statistical testing power. A medication washout is often performed in clinical trials with a prospective design for this reason. Upon first glance, the IOP reduction seemed larger at 12 months in T than in TEx, but this has to be interpreted with caution since the comparison of both groups did not show a difference. It is possible that these differences exist but remain undiscoverable with the numbers used here and are therefore not clinically relevant. A truly larger IOP reduction in $\mathrm{T}$ could have pointed towards a less traumatic TM ablation with this technique. Plasma-mediated ablation is drag free, while dual blade ablation requires that the TM be put under stretch before the cut can be initiated. It is a common occurrence during surgery with the TEx and KDB that drag transmits to the ciliary body band via processes that insert into the TM. Occasionally, this can cause a shallow and inconsequential cyclodialysis to form. It is also not unusual with excisional devices to catch the scleral spur, the outer wall of Schlemm's canal or the innermost part of the roof of Schlemm's canal, potentially causing trauma. A full TM strip can also not always be excised, which causes the procedure in such patients to be more akin to a traditional goniotomy, including a chance that TM lips might reapproximate as is known to occur in trabeculotomy [13]. These concerns do not exist with $\mathrm{T}$.

As is common to minimally invasive glaucoma surgeries in general, only a handful of complications occurred, too few for a meaningful statistical comparison. Both TEx and T can be considered very safe as only one serious and temporary complication occurred, toxic anterior chamber syndrome, that resolved with medical treatment. In comparison to our complications of $7 \%$ in TEx and $2 \%$ in $\mathrm{T}$, previous KDB studies reported complication rates ranging from $7 \%$ to $14 \%[16,31$, 32].

Our study had several limitations. The design was chosen in order to display IOP differences between TEx and T that cannot be easily detected without matching. We did so because there is already a considerable body of evidence demonstrating the effectiveness of excisional ab interno trabeculectomy, both ex vivo $[2,12,14]$ and in vivo $[8,15,16]$. Our patients had a relatively low baseline IOP with a small IOP and medication reduction. It is likely that patients with a higher baseline IOP would 
have experienced a larger IOP reduction, as seen in prior studies [33, 34]. Samesession cataract surgery does not have a clinically significant impact on $\mathrm{T}[21,35]$. While it is reasonable to assume that the same applies to TEx, this has not been established yet.

In conclusion, this study applied matching to display small, device-specific differences between $\mathrm{T}$ and TEx, a plasma-mediated and excisional removal technique of TM, respectively. A small IOP and medication reduction occurred in both, despite a relatively low baseline IOP. There were no major device-specific differences.

Funding/ Support: Unrestricted departmental grant

Conflicts of Interest Statement: None of the authors have any proprietary interests or conflicts of interest related to this submission.

Data Availability: Data is available from the corresponding author on request.

Code Availability: Not applicable.

Ethics Approval: This study was approved by our Institutional Review Board (IRB), study code: 21122020 1920. Consent was waived by the IRB.

Consent for Participation: Not applicable.

Consent for Publication: All listed authors consent to the publication of this manuscript.

\section{References}

1. Esfandiari H, Chen S, Loewen RT, et al (2020) Ab-interno trabecular meshwork incision, ablation, and disruption. In: Samples JR, Ahmed IIK (eds) Current Developments in Glaucoma Surgery and MIGS. Kugler Publications, pp 137-156

2. Wang C, Dang Y, Shah P, et al (2020) Intraocular pressure reduction in a pigmentary glaucoma model by Goniotome Ab interno trabeculectomy. PLoS One 15:e0231360. https://doi.org/10.1371/journal.pone.0231360

3. Akil H, Chopra V, Huang A, et al (2016) Clinical Results of Ab Interno Trabeculotomy Using the Trabectome in Patients with Pigmentary Glaucoma compared to Primary Open Angle Glaucoma. Clin Experiment Ophthalmol. https://doi.org/10.1111/ceo.12737

4. Esfandiari H, Shah P, Torkian P, et al (2019) Five-year clinical outcomes of combined phacoemulsification and trabectome surgery at a single glaucoma center. Graefes Arch Clin Exp Ophthalmol 257:357-362. https://doi.org/10.1007/s00417-0184146-y

5. Dang Y, Roy P, Bussel II, et al (2016) Combined analysis of trabectome and phaco-trabectome outcomes by glaucoma severity. F1000Res 5:762. https://doi.org/10.12688/f1000research.8448.2

6. Dang Y, Kaplowitz K, Parikh HA, et al (2016) Steroid-induced glaucoma treated with trabecular ablation in a matched comparison with primary open-angle glaucoma. Clin Experiment Ophthalmol. https://doi.org/10.1111/ceo.12796

7. Minckler DS, Baerveldt G, Alfaro MR, Francis BA (2005) Clinical results with the Trabectome for treatment of open-angle glaucoma. Ophthalmology 112:962-967. https://doi.org/10.1016/j.ophtha.2004.12.043

8. SooHoo JR, Seibold LK, Kahook MY (2015) Ab interno trabeculectomy in the adult patient. Middle East Afr J Ophthalmol 22:25-29. https://doi.org/10.4103/0974-9233.148345

9. Ramjiani V, Mudhar H-S, Julian T, Auger G (2021) Sampling trabecular meshwork using TrabEx. BMC Ophthalmol 21:138. https://doi.org/10.1186/s12886-021-01895-6

10. Lee DA (1990) Surgical Instrument. Patent

11. Gedde SJ, Herndon LW, Brandt JD, et al (2012) Postoperative complications in the Tube Versus Trabeculectomy (TVT) study during five years of follow-up. Am J Ophthalmol 153:804-814.e1. https://doi.org/10.1016/j.ajo.2011.10.024

12. Wang C, Dang Y, Waxman S, et al (2017) Angle stability and outflow in dual blade ab interno trabeculectomy with active versus passive chamber management. PLoS One 12:e0177238. https://doi.org/10.1371/journal.pone.0177238

13. Luntz MH, Livingston DG (1977) Trabeculotomy ab externo and trabeculectomy in congenital and adult-onset glaucoma. Am J Ophthalmol 83:174-179. https://doi.org/10.1016/0002-9394(77)90612-2

14. Dang Y, Wang C, Shah P, et al (2018) Outflow enhancement by three different ab interno trabeculectomy procedures in a porcine anterior segment model. Graefes Arch Clin Exp Ophthalmol 256:1305-1312. https://doi.org/10.1007/s00417-0183990-0

15. Berdahl JP, Gallardo MJ, ElMallah MK, et al (2018) Six-Month Outcomes of Goniotomy Performed with the Kahook Dual Blade as a Stand-Alone Glaucoma Procedure. Adv Ther 35:2093-2102. https://doi.org/10.1007/s12325-018-0803-0 
16. Ventura-Abreu N, García-Feijoo J, Pazos M, et al (2021) Twelve-month results of ab interno trabeculectomy with Kahook Dual Blade: an interventional, randomized, controlled clinical study. Graefes Arch Clin Exp Ophthalmol. https://doi.org/10.1007/s00417-021-05213-0

17. Iacus SM, King G, Porro G (2012) Causal Inference without Balance Checking: Coarsened Exact Matching. Polit Anal 20:1-24. https://doi.org/10.1093/pan/mpr013

18. Esfandiari H, Taubenslag K, Shah $\mathrm{P}$, et al (2019) Two-year data comparison of ab interno trabeculectomy and trabecular bypass stenting using exact matching. J Cataract Refract Surg 45:608-614. https://doi.org/10.1016/j.jcrs.2018.12.011

19. Al Yousef Y, Strzalkowska A, Hillenkamp J, et al (2020) Comparison of a second-generation trabecular bypass (iStent inject) to ab interno trabeculectomy (Trabectome) by exact matching. Graefes Arch Clin Exp Ophthalmol 258:2775-2780. https://doi.org/10.1007/s00417-020-04933-z

20. Weiner AJ, Weiner Y, Weiner A (2020) Intraocular Pressure after Cataract Surgery Combined with Ab-interno Trabeculectomy versus Trabecular Micro-bypass Stent; an Intra-subject Same-surgeon Comparison. J Glaucoma. https://doi.org/10.1097/IJG.0000000000001547

21. Neiweem AE, Bussel II, Schuman JS, et al (2016) Glaucoma Surgery Calculator: Limited Additive Effect of Phacoemulsification on Intraocular Pressure in Ab Interno Trabeculectomy. PLoS One 11:e0153585. https://doi.org/10.1371/journal.pone.0153585

22. Capitena Young CE, Ammar DA, Seibold LK, et al (2018) Histopathologic Examination of Trabecular Meshwork Changes After Trabecular Bypass Stent Implantation. J Glaucoma 27:606-609. https://doi.org/10.1097/IJG.0000000000000968

23. Shah M, Campos-Möller X, Werner L, et al (2018) Midterm failure of combined phacoemulsification with trabecular microbypass stenting: Clinicopathological analysis. J Cataract Refract Surg 44:654-657. https://doi.org/10.1016/j.jcrs.2018.03.030

24. Roy P, Loewen RT, Dang Y, et al (2017) Stratification of phaco-trabectome surgery results using a glaucoma severity index in a retrospective analysis. BMC Ophthalmol 17:30. https://doi.org/10.1186/s12886-017-0421-7

25. Dang Y-L, Wang X, Dai W-W, et al (2018) Two-year outcomes of ab interno trabeculectomy with the Trabectome for Chinese primary open angle glaucoma: a retrospective multicenter study. Int J Ophthalmol 11:945-950. https://doi.org/10.18240/ijo.2018.06.08

26. Kostanyan T, Shazly T, Kaplowitz KB, et al (2017) Longer-term Baerveldt to Trabectome glaucoma surgery comparison using propensity score matching. Graefes Arch Clin Exp Ophthalmol 255:2423-2428. https://doi.org/10.1007/s00417-0173804-9

27. Strzalkowska A, Strzalkowski P, Al Yousef Y, et al (2021) Exact matching of trabectome-mediated ab interno trabeculectomy to conventional trabeculectomy with mitomycin C followed for 2 years. Graefes Arch Clin Exp Ophthalmol 259:963-970. https://doi.org/10.1007/s00417-020-05031-w

28. Tojo N, Hayashi A (2020) The Outcomes of Trabectome Surgery in Patients with Low, Middle, and High Preoperative Intraocular Pressure. Clin Ophthalmol 14:4099-4108. https://doi.org/10.2147/OPTH.S285883

29. Nakamura K, Honda R, Soeda S, et al (2021) Factors associated with achieving intraocular pressure lower than $15 \mathrm{mmHg}$ by Trabectome surgery in primary open-angle glaucoma. Sci Rep 11:14308. https://doi.org/10.1038/s41598-021-93711-w

30. Chang EK, Gupta S, Chachanidze M, et al (2021) Safety and efficacy of microinvasive glaucoma surgery with cataract extraction in patients with normal-tension glaucoma. Sci Rep 11:8910. https://doi.org/10.1038/s41598-021-88358-6

31. Hirabayashi MT, King JT, Lee D, An JA (2019) Outcome of phacoemulsification combined with excisional goniotomy using the Kahook Dual Blade in severe glaucoma patients at 6 months. Clin Ophthalmol 13:715-721. https://doi.org/10.2147/OPTH.S196105

32. Al Habash A, Albuainain A (2021) Long term outcome of combined phacoemulsification and excisional goniotomy with the Kahook Dual Blade in different subtypes of glaucoma. Sci Rep 11:10660. https://doi.org/10.1038/s41598-021-90223-5

33. Kaplowitz K, Bussel II, Honkanen R, et al (2016) Review and meta-analysis of ab-interno trabeculectomy outcomes. Br J Ophthalmol 100:594-600. https://doi.org/10.1136/bjophthalmol-2015-307131

34. Fallano K, Bussel I, Kagemann L, et al (2017) Training strategies and outcomes of ab interno trabeculectomy with the trabectome. F1000Res 6:67. https://doi.org/10.12688/f1000research.10236.1

35. Parikh HA, Bussel II, Schuman JS, et al (2016) Coarsened Exact Matching of Phaco-Trabectome to Trabectome in Phakic Patients: Lack of Additional Pressure Reduction from Phacoemulsification. PLoS One 11:e0149384. https://doi.org/10.1371/journal.pone.0149384 


\section{$\underline{\text { Tables }}$}

Table 1

Table 1 Matched baseline characteristics of TEx and T

\begin{tabular}{|c|c|c|c|}
\hline Variable & $\begin{array}{c}\text { TEx+ } \\
(\mathbf{n}=\mathbf{5 3})\end{array}$ & $\begin{array}{c}\text { T } \\
\text { (n=53) }\end{array}$ & $\begin{array}{c}\text { p-value } \\
\text { TEx vs. T }\end{array}$ \\
\hline Age (years) & $73.7 \pm 8.8$ & $71.5 \pm 9.9$ & 0.24 \\
\hline $\begin{array}{c}\text { Female (n, \%) } \\
\text { Male (n, \%) }\end{array}$ & $\begin{array}{c}31(58.5 \%) \\
22(41.5 \%)\end{array}$ & $29(54.7 \%)$ \\
\hline $\begin{array}{c}\text { POAG (n, \%) } \\
\text { LTG (n, \%) }\end{array}$ & $39(73.6 \%)$ & $1.3 \%)$ & 1.0 \\
\hline IOPвL (mmHg) & $14(26.4 \%)$ & $14(26.4 \%)$ & 0.97 \\
\hline MedBL & $16.6 \pm 4.6$ & $16.6 \pm 4.6$ & $<0.001^{*}$ \\
\hline VAвL & $2.1 \pm 1.4$ & $1.4 \pm 1.1$ & 0.07 \\
\hline With Phaco (n, \%) & 0.7 & 0.6 & 0.8 \\
\hline
\end{tabular}

Med $\mathrm{BL}_{\mathrm{L}}=$ number of medications at baseline; $\mathrm{VA}_{\mathrm{BL}}=$ visual acuity at baseline; With Phaco $=$ in combination with cataract surgery; ${ }^{*}$ p-value $<0.05$ 
Table 2

Table 2 Follow-up parameters compared between TEx and T

\begin{tabular}{|c|c|c|c|c|}
\hline Variable/Group & $\begin{array}{c}\text { TEx } \\
(n=53)\end{array}$ & $\begin{array}{c}T \\
(n=53)\end{array}$ & $\begin{array}{l}\text { p-value } \\
\text { TEx vs. T }\end{array}$ & $\begin{array}{c}\text { p-value } \\
\text { baseline vs. follow-up } \\
(\mathrm{TEx} / \mathrm{T})\end{array}$ \\
\hline $\begin{array}{c}\mathrm{IOPBL}_{\mathrm{BL}} \\
(\mathrm{mmHg})\end{array}$ & $\begin{array}{l}16.5 \pm 4.6 \\
(\mathrm{n}=53)\end{array}$ & $\begin{array}{l}16.5 \pm 4.6 \\
(n=53)\end{array}$ & 0.97 & \\
\hline $\begin{array}{c}\mathrm{IOP}_{6} \\
(\mathrm{mmHg})\end{array}$ & $\begin{array}{l}14.8 \pm 4.3 \\
(\mathrm{n}=46)\end{array}$ & $\begin{array}{l}13.4 \pm 3.4 \\
(\mathrm{n}=52)\end{array}$ & 0.12 & $0.002^{*} /<0.001^{*}$ \\
\hline $\begin{array}{c}\mathrm{IOP}_{12} \\
(\mathrm{mmHg})\end{array}$ & $\begin{array}{l}14.9 \pm 6.0 \\
(\mathrm{n}=40)\end{array}$ & $\begin{array}{l}14.1 \pm 3.8 \\
(\mathrm{n}=53)\end{array}$ & 0.99 & $0.13 /<0.001^{*}$ \\
\hline $\begin{array}{l}\text { MedBL } \\
\text { (drops) }\end{array}$ & $\begin{array}{l}2.1 \pm 1.4 \\
(\mathrm{n}=53)\end{array}$ & $\begin{array}{l}1.4 \pm 1.1 \\
(n=53)\end{array}$ & $0.004^{*}$ & \\
\hline $\begin{array}{l}\text { Med }_{6} \\
\text { (drops) }\end{array}$ & $\begin{array}{l}1.7 \pm 1.5 \\
(\mathrm{n}=47)\end{array}$ & $\begin{array}{l}0.5 \pm 0.8 \\
(\mathrm{n}=52)\end{array}$ & $<0.001^{*}$ & $0.03^{*} /<0.001^{*}$ \\
\hline $\begin{array}{l}\text { Med12 }_{12} \\
\text { (drops) }\end{array}$ & $\begin{array}{l}1.5 \pm 1.3 \\
(\mathrm{n}=40)\end{array}$ & $\begin{array}{l}0.6 \pm 1.0 \\
(n=53)\end{array}$ & $<0.001^{*}$ & $0.005^{*} /<0.001^{*}$ \\
\hline $\begin{array}{c}\text { Complications } \\
(\mathrm{n}, \%)\end{array}$ & $4(7.5 \%)$ & $1(1.9 \%)$ & 0.17 & \\
\hline
\end{tabular}

$\mathrm{IOP}_{\mathrm{BL}}=\mathrm{IOP}$ at baseline; $\mathrm{IOP}_{6}=\mathrm{IOP}$ at 6 months; IOP $12=\mathrm{IOP}$ at 12 months; Med $=$ medication; $\underline{V A}=$ visual acuity; ${ }^{*} p$-value $<0.05$ 
Table 3

Table 3 Unmatched Comparison of TEx and T

\begin{tabular}{|c|c|c|c|c|}
\hline Variable/Group & $\begin{array}{c}\text { TEx } \\
(\mathrm{n}=56)\end{array}$ & $\begin{array}{c}\mathrm{T} \\
(\mathrm{n}=99)\end{array}$ & $\begin{array}{l}\text { p-value } \\
\text { TEx vs. T }\end{array}$ & $\begin{array}{c}\text { p-value } \\
\text { baseline vs. follow-up } \\
(\mathrm{TEx} / \mathrm{T})\end{array}$ \\
\hline $\begin{array}{c}\text { Age } \\
\text { (Years) }\end{array}$ & $\begin{array}{l}74.0 \pm 9.1 \\
(\mathrm{n}=56)\end{array}$ & $\begin{array}{c}68.84 \pm 10.4 \\
(\mathrm{n}=99)\end{array}$ & $0.002^{*}$ & \\
\hline $\begin{array}{c}\text { Gender Ratio } \\
\text { (M:F) }\end{array}$ & $1: 1.4$ & $1: 1.25$ & 0.68 & \\
\hline $\begin{array}{c}\text { Phaco/IOL } \\
(n, \%)\end{array}$ & $45(80.4 \%)$ & $86(86.9 \%)$ & 0.28 & \\
\hline $\begin{array}{c}\text { IOPBL } \\
(\mathrm{mmHg})\end{array}$ & $\begin{array}{c}17.5 \pm 5.9 \\
(n=56)\end{array}$ & $\begin{array}{c}17.1 \pm 5.1 \\
(n=99)\end{array}$ & 0.92 & \\
\hline $\begin{array}{c}\mathrm{IOP}_{6} \\
(\mathrm{mmHg})\end{array}$ & $\begin{array}{c}14.8 \pm 4.2 \\
(\mathrm{n}=49)\end{array}$ & $\begin{array}{l}13.6 \pm 3.3 \\
(n=95)\end{array}$ & 0.11 & $0.001^{*} /<0.001^{*}$ \\
\hline $\begin{array}{c}\mathrm{IOP}_{12} \\
(\mathrm{mmHg})\end{array}$ & $\begin{array}{c}15.1 \pm 5.9 \\
(\mathrm{n}=44)\end{array}$ & $\begin{array}{l}14.3 \pm 3.9 \\
(\mathrm{n}=99)\end{array}$ & 0.82 & $0.037^{*} /<0.001^{*}$ \\
\hline $\begin{array}{c}\text { MedвL } \\
\text { (Drops) }\end{array}$ & $\begin{array}{l}2.2 \pm 1.3 \\
(\mathrm{n}=56)\end{array}$ & $\begin{array}{l}1.4 \pm 1.2 \\
(\mathrm{n}=99)\end{array}$ & $0.001^{*}$ & \\
\hline $\begin{array}{c}\text { Med }_{6} \\
\text { (Drops) }\end{array}$ & $\begin{array}{l}1.7 \pm 1.5 \\
(\mathrm{n}=50)\end{array}$ & $\begin{array}{l}0.6 \pm 0.9 \\
(\mathrm{n}=95)\end{array}$ & $<0.001^{*}$ & $0.03^{*} /<0.001^{*}$ \\
\hline $\begin{array}{c}\text { Med }_{12} \\
\text { (Drops) }\end{array}$ & $\begin{array}{l}1.6 \pm 1.3 \\
(\mathrm{n}=44)\end{array}$ & $\begin{array}{l}0.7 \pm 1.0 \\
(\mathrm{n}=99)\end{array}$ & $<0.001^{*}$ & $0.005^{*} /<0.001^{*}$ \\
\hline
\end{tabular}

$\mathrm{IOP}_{\mathrm{BL}}=\mathrm{IOP}$ at baseline; $\mathrm{IOP}_{6}=\mathrm{IOP}$ at 6 months; $\mathrm{IOP}_{12}=\mathrm{IOP}$ at 12 months; Med = medication; $\mathrm{VA}=$ visual acuity; ${ }^{*} \mathrm{p}$-value $<0.05$. 
Table 4

Table 4 Success rates of TEx and T for IOP and medication count

\begin{tabular}{|c|c|c|c|}
\hline Success / Group & TrabEx+ & Trabectome & p-value \\
\hline $\begin{array}{l}\text { IOP (OR criterion) } \\
6 \text { months } \\
(\mathrm{n}, \%)\end{array}$ & $43 / 46(93.5 \%)$ & $50 / 52(96.0 \%)$ & 0.55 \\
\hline $\begin{array}{l}\text { IOP (OR criterion) } \\
12 \text { months } \\
\text { (n, \%) }\end{array}$ & $38 / 40(95.0 \%)$ & $52 / 53(98.1 \%)$ & 0.40 \\
\hline $\begin{array}{l}\text { IOP (AND criterion) } \\
6 \text { months } \\
(\mathrm{n}, \%)\end{array}$ & $21 / 46(45.6 \%)$ & $21 / 52(40.4 \%)$ & 0.60 \\
\hline $\begin{array}{l}\text { IOP (AND criterion) } \\
12 \text { months } \\
\text { (n, \%) }\end{array}$ & $13 / 40(32.5 \%)$ & $17 / 53(32.1 \%)$ & 0.97 \\
\hline $\begin{array}{l}\text { IOP (AND criterion) AND } \\
\text { medication reduction, } \\
6 \text { months }(\mathrm{n}, \%)\end{array}$ & $7 / 46(15.2 \%)$ & $7 / 52(13.5 \%)$ & 0.80 \\
\hline $\begin{array}{l}\text { IOP (AND criterion) AND } \\
\text { Medication Reduction, } \\
12 \text { months (n, \%) }\end{array}$ & $4 / 40(10.0 \%)$ & $4 / 53(7.7 \%)$ & 0.68 \\
\hline $\begin{array}{l}\text { Medication Reduction, } \\
6 \text { months (n, \%) }\end{array}$ & $20 / 46(43.4 \%)$ & $30 / 52(57.7 \%)$ & 0.16 \\
\hline $\begin{array}{c}\text { Medication Reduction, } \\
1 \text { year }(\mathrm{n}, \%)\end{array}$ & $17 / 40(42.5 \%)$ & $28 / 53(52.8 \%)$ & 0.32 \\
\hline
\end{tabular}

OR criterion = IOP decrease of $\geq 20 \%$ or final IOP $\leq 21 \mathrm{mmHg}$; AND criterion = IOP decrease of $\geq 20 \%$ and final IOP $\leq 21 \mathrm{mmHg}$; med reduction = at least 1 drop less compared to baseline 


\section{Figures}

Figure 1

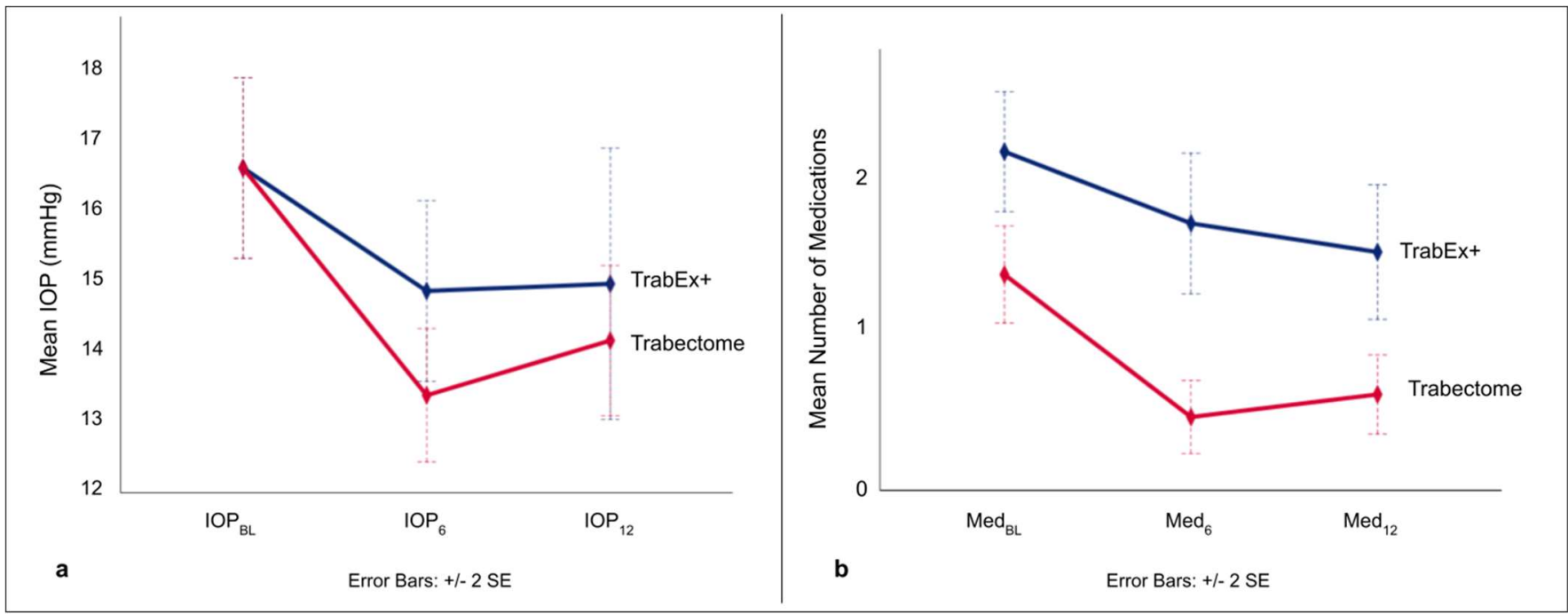

Fig. 1 Mean intraocular pressure (IOP) (a) and number of medications (b) for TrabEx+ (TEx, blue) and Trabectome ( $\mathrm{T}$, red). A) T and TEx had a low baseline IOP. An IOP reduction occurred in both, but was more pronounced in T. B) TEx took more medications than $\mathrm{T}$ at baseline. A reduction in medications was achieved in both $\mathrm{T}$ and TEx, and to a similar extent. IOP $\mathrm{BL}=\mathrm{IOP}$ at baseline; $\mathrm{IOP}_{6}=\mathrm{IOP}$ at 6 months; $\mathrm{IOP}_{12}=\mathrm{IOP}$ at 12 months; Med $\mathrm{BL}=$ number of medications at baseline; Med $6=$ number of medications 6 months after surgery; Med $_{12}=$ number of medications 1 year after surgery; $\mathrm{SE}=$ standard error. 